\title{
Opening characteristics of three-cusp tissue heart valves
}

\author{
P. D. SWALES, M.P. HOLDEN, D. DOW SON, \\ and M.I. IONESCU \\ Mechanical Engineering and Cardiothoracic Surgery Departments, University of Leeds and \\ The General Infirmary at Leeds
}

\begin{abstract}
Since April 1969, frame-mounted three-cusp fascia lata and pericardial valves have been used in over 200 patients for heart valve replacement. Six autologous fascia lata valves have been removed from the mitral position because of regurgitation produced by shrinkage of one or two cusps. To elucidate the cause and mechanism of graft failure the opening characteristics of fascia lata and Silastic valves were studied in a steady state flow rig.

In virtually all valves examined the cusps opened in sequence and the order in which the cusps of a particular valve opened was maintained irrespective of its position in the testing apparatus. Under the conditions prevailing in this experiment the sequential opening of the cusps seems to be inherent in the design of the valve. Inequalities in the size and shape of the cusps or in the physical properties of the material accentuated this phenomenon.

Fully open valves were geometrically similar and the relationship between pressure gradient, flow rate, and valve diameter has the form: $\mathrm{pd}^{4}=4,600 \mathrm{Q}^{2}$. This formula will apply to all such valves tested in water, irrespective of material or size, provided that they are fully open.

The experiment has shown that the pressure gradient across the valve increases rapidly as the diameter of the valve is reduced and that with reduction in valve diameter a decreased flow rate is required for complete valve opening.

It is postulated that in patients with postoperative low cardiac output, large grafts in the mitral position may not open fully and consequently the cusp or cusps with little or no mobility may undergo structural changes leading to fibrosis with thickening or atrophy.
\end{abstract}

Results obtained with heart valve replacement continue to improve due to better surgical techniques and improvements in both types of valve substitutes-prosthetic devices and tissue valves.

Although none of these valves is ideal, they provide useful palliation and give good promise for further improvement.

Since April 1969 we have used 'man-made', frame-mounted, three-cusp tissue valves for heart valve replacement in over 200 patients (Ionescu and Ross, 1969 ; Ionescu, Deac, Whitaker, and Wooler, 1972a).

Autologous and homologous fascia lata and heterologous pericardium have been used for the construction of valves.

During the follow-up period which extends to over three years it became apparent that these tissue valves have performed differently in the two main positions in the heart. In the aortic

1This work was supported in part by a grant from the British Heart Foundation position the results have been very encouraging in 90 patients; no graft failure has occurred and the clinical and haemodynamic results are good (Ionescu et al., 1972b). In the mitral position, although the majority of 115 patients operated upon have been benefited by surgery, six grafts had to be removed because of graft failure. The appearance of the autologous fascial valves removed at re-operation from the mitral position has always been similar. One or two cusps were retracted and thickened, rendering the valve incompetent (Holden and Ionescu, 1973b).

The possible causes of fascia lata graft failure in the mitral position are being continuously investigated in our institution. Infection and rejection phenomena are considered to be unlikely causes (Ionescu et al., 1972a ; Silver and Trimble, 1972 ; Hudson, 1970). Biological and biochemical factors cannot be held entirely responsible for graft failure at least in the present state of our knowledge (Trimble, 1972). 
Mechanical reasons for valve dysfunction and failure have formed our first working hypothesis for a scientific explanation of this phenomenon. The closure mechanism of three-cusp heart valves has been extensively investigated (Bellhouse, 1972 ; Holden and Ionescu, 1973a).

The purpose of this report is to describe the initial results of a study concerned with the opening mechanism of stented three-cusp tissue heart valves and to discuss the potential relationship between abnormalities in the opening phase and the failure of grafts in the mitral position.

\section{MATERIAL AND METHOD}

The apparatus shown diagrammatically in Fig. 1 was used for testing all the valves described. A steady flow rate was maintained by a 'MONO' positive displacement pump. The flow rate could be varied by means of two valves and a bleed in the delivery line. A constant back pressure of $22 \mathrm{mmHg}$ was provided by a small head tank. Flow rates were determined using a measuring cylinder and a stop watch. The pressure gradient was measured by an inclined water manometer. The test fluid was water in all studies. A Perspex chamber in the circuit allowed visual and photographic observations of the valves.

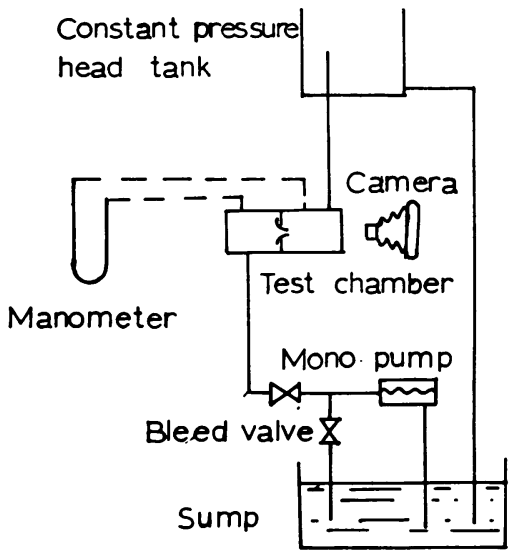

FIG. 1. Schematic representation of the apparatus used for valve testing.

The valves tested were three-cusp structures mounted on Dacron-covered titanium frames (Fig. 2) and manufactured as previously described (Ionescu et al., 1970 ; Bartek, Holden, and Ionescu, 1973).

Two types of material were used for the construction of the valves-fascia lata and reinforced Silastic.

Visual and photographic observations of the mechanism and sequence of opening of each cusp were made.

The pressure gradient across the valve and the flow rate necessary for cusp opening were recorded.

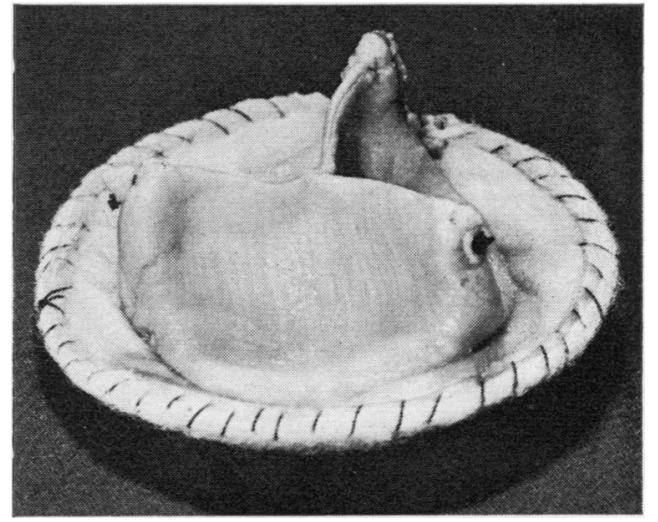

FIG. 2. Outflow aspect of a three-cusp tissue valve mounted on a Dacron-covered metal frame.

Valves having different internal diameters and supporting prong heights were studied and compared in order to assess the effects of these parameters on the pressure gradient and flow rate required to open the cusps.

\section{RESULTS}

FASCIA LATA VALVES Eight nominally identical fascia lata valves were used in this series.

Human fascia lata was obtained from the postmortem room up to 36 hours after death and mounted on support frames with an internal diameter of $24 \mathrm{~mm}$ and parallel prongs with a height of $19 \mathrm{~mm}$. The fascial grafts were maintained in normal saline solution at $27^{\circ} \mathrm{C}$ until the studies were carried out (usually less than 72 hours after preparation). The results of the tests are given in Table $I$.

Under the test conditions the opening sequence of the cusps could be observed. At low flow rates, less than $11 . / \mathrm{min}$, the cusps parted at the centre

\section{TAB LE I}

NONPULSATILE FLOW RATES AT WHICH COMPLETE OPENING OF ALL THREE CUSPS OCCURRED AND PRES SURE GRADIENTS WITH OPENING OF EACH COMPONENT

\begin{tabular}{c|c|c|c|c}
\hline & \multicolumn{2}{|c|}{$\begin{array}{c}\text { Pressure Gradient (mmHg) } \\
\text { Valve } \\
\text { with Sequential Opening } \\
\text { of the Cusps }\end{array}$} & $\begin{array}{c}\text { Flow Rate (1./min) } \\
\text { for Complete Opening } \\
\text { of All Three Cusps }\end{array}$ \\
\cline { 2 - 4 } & 1 Cusp & 2 Cusps & 3 Cusps & \\
\hline 1 & 0.02 & 0.26 & 0.37 & 5.4 \\
2 & 0.06 & 0.21 & 0.47 & 4.4 \\
3 & 0.04 & 0.13 & 0.38 & 5.0 \\
4 & 0.02 & 0.06 & 0.13 & 3.0 \\
5 & 0.04 & 0.50 & 0.50 & 7.0 \\
7 & 0.15 & 0.35 & 0.37 & 4.4 \\
7 & 0.10 & 0.21 & 0.29 & 0.4 \\
8 & 0.02 & 0.16 & 0.16 & 2.5 \\
\hline
\end{tabular}

${ }^{1}$ All valves had an internal diameter of the support frame of $24 \mathrm{~mm}$. The test fluid was water. 

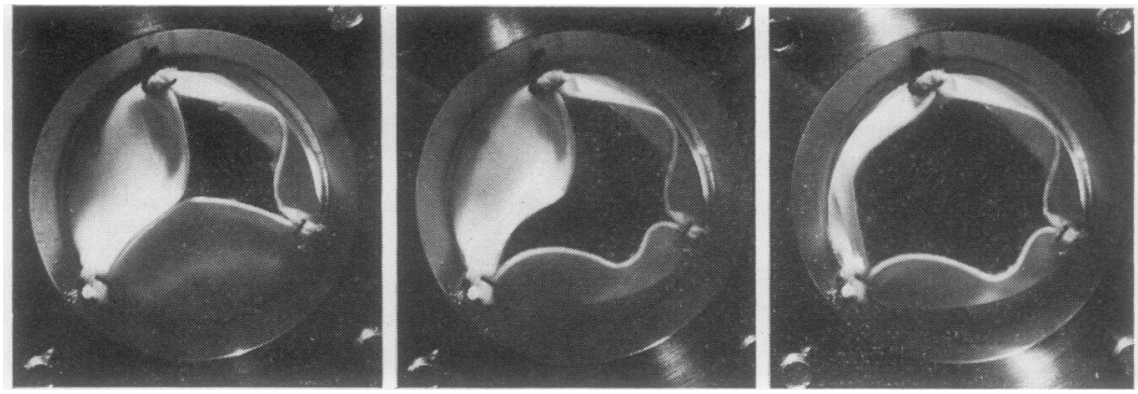

FIG. 3. Tissue valve in the testing apparatus showing the sequential opening of the cusps. The flowrate was increased in steps from 0.5 to 1.5 and to 3 litres/minute (from left to right). This valve was made of tissue with different thicknesses for each cusp in order to exaggerate the sequential opening.

of the free edges. This condition was maintained for a short time despite a gradually increasing flow rate. At some point one cusp would suddenly open. The tissue appeared to unfold from the commissures in a continuous movement, and once started the cusp would often open completely without any increase in flow rate. At the same time the pressure gradient recorded across the valve fell. Further increases of flow rate produced similar sequences of events for the second and third cusps (Fig. 3). It was noted that the pressure gradient usually dropped by about $30 \%$ of that present just before the opening of the cusp when the third cusp opened, although differences of as much as $50 \%$ were occasionally observed. Further increases in flow rate tended to remove any residual slack in the cusps, causing them to balloon outwards.

An examination of the order in which the cusps of a particular valve opened showed that, in general, the opening sequence was maintained when the valve was rotated in its mount, indicating that the sequence was a characteristic of the valve and not of the apparatus. However, in two valves the first cusp to open differed in subsequent tests.

The pressures recorded in Table $I$ are the steady state pressures after the cusps had opened, since it proved difficult to record consistently the pressures just before opening. It will be noted that the variation from valve to valve was a factor of about four on pressure and nearly three on flow rate. No correlation could be drawn between the pressure at which the first cusp opened and the final performance of the valve.

SILASTIC VALVES In order to eliminate one variable from the study, reinforced Silastic (a
T A B L E I I

PRESSURE GRADIENT AND FLOW RATE AT WHICH ALL $\overrightarrow{0}$ THREE CUSPS FIRST OPENED IN A SERIES OF SIX SIMILAR

\begin{tabular}{|c|c|c|c|}
\hline $\begin{array}{c}\text { Valve } \\
\text { Number }\end{array}$ & $\begin{array}{c}\text { Pressure Gradient } \\
(\mathrm{mmHg})\end{array}$ & $\underset{\text { (J./min) }}{\text { Flow Rate }}$ & $\omega \frac{\mathrm{p}}{3}$ \\
\hline $\begin{array}{l}1 \\
2 \\
3 \\
4 \\
5^{1} \\
6^{1}\end{array}$ & $\begin{array}{l}0.59 \\
0.58 \\
0.78 \\
0.66 \\
1.17 \\
0.44\end{array}$ & $\begin{array}{r}5.9 \\
6.1 \\
7.4 \\
7.1 \\
10.0 \\
4.8\end{array}$ & 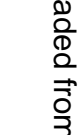 \\
\hline
\end{tabular}

${ }^{1}$ The appearance of valves 5 and 6 can be seen in Figure 4 .

medical grade silicone rubber $^{1}$ ) of $0.15 \mathrm{~mm}$ thick ness was used for the manufacture of a series of six valves. The frame used was the same as that which supported the fascia lata valves.

These valves showed the same general charac teristics as the fascia lata valves in the manner in which they opened but the pressure gradients and flow rates were higher. Table II lists the results obtained with Silastic valves.

The variation, from valve to valve, of the flows rate necessary to achieve complete opening was less than that noted with fascia lata but was still present. With this thin, relatively stiff materiales differences in manufacture were more readilye visible to the eye. It was evident that valves which looked similar in shape did show similar func $\$$ tional characteristics. The existence of creases or distortions in the Silastic valve cusps caused varia bility, although the effect of such variations wa not always detrimental (Fig. 4).

A series of five Silastic valves with an inside diameter of 18 to $26 \mathrm{~mm}$ was used to assess the effect of valve size on the flow rate required to 1Dow Corning Medical Products, Midland, Michigan, U.S.A. 

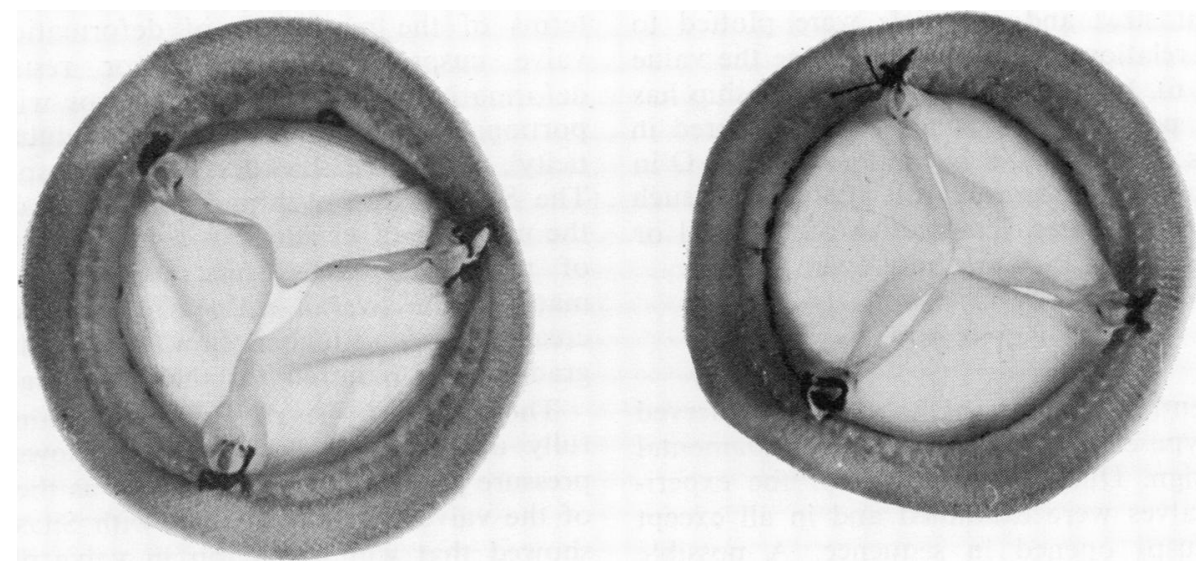

FIG. 4. Two similar valves made of reinforced Silastic demonstrating imperfections in manufacture. The valve on the left contains several creases and some superfluous material, yet it opened fully at less than half the flow rate required for the complete opening of the 'better' valve on the right.

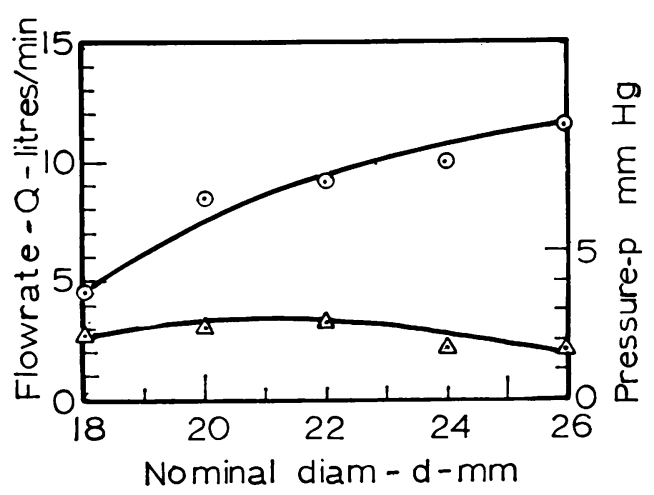

FIG. 5. Flow rate and pressure gradient at complete opening of Silastic valves of different sizes (internal diameter of the support frame in millimetres): $\bigcirc=$ flow rate; $\Delta=$ pressure gradient.

open all three cusps. The results are shown in Figure 5. As expected, the required flow rate increased with increasing diameter, although the pressure gradient at the opening point remained approximately constant in each case. A similar series of tests, but with the valve diameter constant and the height of the prongs varied in steps from 15 to $22.5 \mathrm{~mm}$, showed no significant differences in pressure gradient or flow rate for complete opening.

FLOW RATES AND PRESSURE LOSSES IN OPEN VALVES It was observed that despite the variation in the opening characteristics all valves when fully open were geometrically similar. Under these conditions it can be shown that the rela-

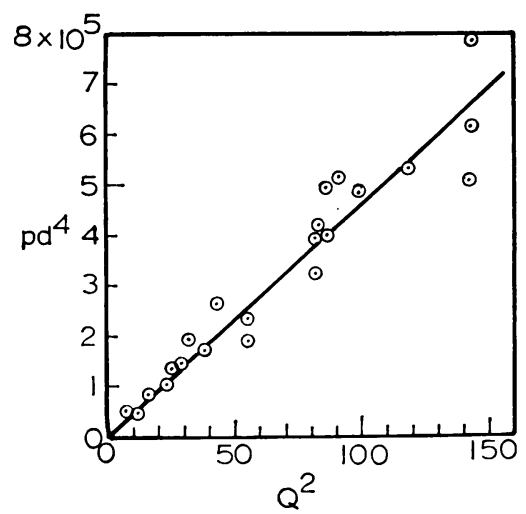

FIG. 6. For valves fully open the parameters obey the approximate relationship $P d^{4}=4,600 Q^{2}$ as shown by the graph above, where $p$ is the pressure gradient across the valve in millimetres of mercury, $d$ the support frame diameter in millimetres, and $Q$ the flow rate in litres/minute. This formula applies to all types of material when water is the test fluid. The value of the constant is unlikely to be widely different with blood.

tionship between pressure gradient $p$, flow rate $Q$, and the valve frame diameter $d$ has the form $\mathrm{dp}^{4}=\mathrm{KQ}^{2}$ where $\mathrm{K}$ is a factor which depends on the Reynolds number ${ }^{1}$ based on the flow through the valve. For many applications the value of $K$ is approximately constant. Results from valves

1The Reynolds number is a non-dimensional group of variables, which is associated with the degree of turbulence in a fluid stream. The definition usually adopted is $R=U 1 / v$ where $U$ is the stream. The definition usually adopted is $R=U 1 / v$ where $U$ is the
fluid velocity, 1 the significant dimension, and $v$ the kinematic
viscosity of the fluid. Since the pressure losses in valves or pipes viscosity of the fluid. Since the pressure losses in valves or pipes
are a function of the turbulence of the stream, a knowledge of are a function of the turbulence of the stream, a knowledge of of changing the parameters of the flow state 
of different sizes and materials were plotted to verify this relationship and to determine the value of $\mathrm{K}$ (Fig. 6). In this instance the relationship has the form: $\mathrm{pd}^{4}=4,600 \mathrm{Q}^{2}$ where $\mathrm{p}$ is measured in millimetres of mercury, $d$ in millimetres, and $Q$ in litres/minute. This formula will apply to all such valves tested in water, irrespective of material or size, provided that they are fully open.

\section{DISCUSSION}

The sequential opening of the cusps observed with this type of valve appears to be fundamental to the design. During the course of the experiment 37 valves were examined and in all except one the cusps opened in sequence. A possible explanation for the sequential opening is that the cusps form segments of near spherical shells. A sphere is the strongest form in which a material of uniform thickness can be arranged to oppose a uniform pressure. Initially, the shells are resistant to deformation and flow is permitted only through the small gaps at their junctions. When the pressure increases to the point at which one shell is deformed, the deformation results in a weaker shape and the movement of the cusp becomes progressive. The increase in area available to flow causes a drop in pressure across the valve and a much increased flow rate is necessary before the pressure rises to the point where the second 'shell' collapses and opens. It is thus only necessary for the cusp to differ marginally in shape or physical properties of the material for the phenomenon of sequential opening to be present.

The problem increases in complexity due to the fact that the area exposed to flow does not increase in direct relationship to the number of cusps open. Measurements from photographs showed that with all three cusps open the crosssectional area available to flow at the outflow end of the valve (the free margin of the cusps) is restricted to about $55 \%$ of that nominally available at the inflow end of the valve (the base of the support frame). With only one or two cusps open the outflow end of the valve does not restrict the flow in the same way and the cross-sectional area is proportionally larger. It was estimated that with one cusp open the flow area amounted to $45 \%$ of the area ultimately available, and with two cusps open, to about $75 \%$. This, of course, applies only to the valves tested which were all mounted on to frames with parallel prongs.

The increased flow rates necessary to open the valves of Silastic material can be explained in terms of the mechanics of deformation of the $\overrightarrow{0}$ valve cusps. The 'stiffness' or resistance to음 deformation of the individual cusps will be pro- $\frac{\bar{c}}{\sqrt{2}}$ portional to $\mathrm{Et}^{3}$ where $\mathrm{E}$ is the modulus of elas- $\frac{\mathbb{R}}{\alpha}$ ticity $^{1}$, and $t$ the thickness of the cusp material. The Silastic leaf is thinner than fascia lata, but ${ }_{-}^{\text {s }}$ the modulus of elasticity will be many times that. of the fascia lata. Thus, despite the thinner $\vec{\omega}$ material, the overall stiffness of the valve is in- $\omega$ creased, and a higher flow rate and pressure $\vec{x}$ gradient are required for their opening.

The form of the relationship obtained for $a_{\omega}^{\infty}$ fully open valve, $\mathrm{pd}^{4}=4,600 \mathrm{Q}^{2}$, shows that the pressure gradient increases rapidly as the diameter $\circ$ of the valve is reduced. Tests with Silastic valves음 showed that with reduction in valve diameter $a-$ decreased flow rate is required for complete
valve opening.

Although conclusions drawn from the steady- $\vec{\theta}$ state condition of this experiment cannot be $\omega$ directly applied to the haemodynamic situation of valve function inside the beating heart, these? observations may explain the difference in fascia lata valve performances between the mitral and the aortic positions.

For the same volume of blood passing through both mitral and aortic valves during a cardiac $\frac{3}{3}$ cycle, the valve in the aortic position should open more readily and fully due to its smaller diameter. This may be enhanced by the high pressure developed during left ventricular contraction and the forceful systolic ejection through the aortic valve.

The behaviour of these valves has, however, been examined using high-speed cine-techniques $ᄋ$ in a pulse duplicator and the results are reported separately (Holden, Wooler, Catchpole, ando Ionescu, 1973; Holden and Ionescu, 1973a). Under pulsatile conditions the same valve opening characteristics were observed, although the relationship between flow rate and pressure gradient. $\%$ could not be obtained in the same way.

In the present series of experiments, efforts ${ }_{i}$ were directed to assessing the effect of using watero rather than blood as a test fluid. In terms of theo fluid dynamics of the situation, the main difference between the fluids is one of viscosity, blood having? a kinematic viscosity approximately five times? that of water. The effect of an increase in vis-

IThe modulus of elasticity is a property of a material which is associated with the material's rigidity or stiffiness. It is which is the ratio between the normal stress (or stifness. It is defined as by ratio between the normal stress (applied normal force dividedo resulting foctional area) and the strain (fractional chance in lensth) resulting from the stress. When individual pioces of material ares considered, as opposed to the material itself, the stifiness, or inverse defiection, depends on the relevant dimensions as well as the
elastic modulus 
cosity for a fully open valve would be to increase the pressure gradient for a given flow rate, but the magnitude of the increase is dependent upon the Reynolds number. In this case the Reynolds number appertaining to a $24 \mathrm{~mm}$ valve and a flow of 3 litres/minute is about 5,000 when the test fluid is water. For blood this figure would be of the order of 1,000 . In these circumstances the increase in pressure gradient due to the increased viscosity is unlikely to exceed a factor of two (Spiers, 1962) and could be much less. The effect on the flow rate at which the valve first opens fully is more difficult to predict theoretically, but it could be argued that the increased pressure gradient could cause the cusps to open earlier in a more viscous fluid. Attempts to verify these conclusions experimentally proved abortive as the test fluids chosen affected the properties of the tissue. For instance, a $45 \%$ solution of dextrose in water, which produced a kinematic viscosity of about $5 \mathrm{St}$. was found adversely to affect the fascial tissue. Using a $42 \%$ solution of glycerine in water it was found that the Silastic cusps did open marginally earlier but the pressure gradient flow rate relationship remained unaltered. It was noted, however, that some deterioration of the silicon rubber had been caused by the glycerine, and therefore the test was considered inconclusive. It is probable that, provided the tissue remains unaffected by the blood, the results quoted will be altered only marginally by the change in viscosity.

The point concerning changes in the physical properties of tissue valves with the passage of time is extremely important. Nearly all the fascia lata valves stored in $4 \%$ formaldehyde or $0.2 \%$ glutaraldehyde showed increased stiffness, with the result that higher flow rates were required to produce their complete opening in the testing apparatus. The effects of blood on fascia lata are not yet known.

Lam, Aram, and Munnell (1952), Beall, Morris, Cooley, and De Bakey (1961), and Duran, Manley, and Gunning (1965) found that the cusps of homologous aortic valves inserted into the descending aorta of dogs became thickened and retracted unless the recipient's own aortic valve was made incompetent. They concluded that a transplanted valve would work when a physiological need for this valve was created.

This study has shown that under the conditions prevailing in the experiment, the sequential opening of the cusps is inherent in the design of the valve. However, inequalities in the size and shape of the cusps or in the physical properties of the material used for valve construction accentuate the phenomenon of sequential opening.

In some patients, early after heart surgery an autologous fascia lata valve in the mitral position may not open completely due to the low flow rate available. The valve graft may accommodate the reduced cardiac output with only two or even one cusp open. Consequently, it is plausible to assume that the cusp or cusps with limited or no mobility, being made of 'living' tissue, undergo structural changes, as shown by Lam et al. (1952), Beall et al. (1961), and Duran et al. (1965).

The biological fate of non-functional connective tissue structures is fibrosis with thickening or atrophy. When this occurs in a heart valve graft the function of the graft is severely impaired.

\section{REFERENCES}

Bartek, T., Holden, M. P., and Ionescu, M. I. (1973). Biological tissue heart valves; techniques of construction. Brit. J. Surg. (in press).

Beall, A. C. Jr., Morris, G. C. Jr., Cooley, D. A., and De Bakey, M. E. (1961). Homotransplantation of the aortic valve. J. thorac. cardiovasc. Surg., 42, 497.

Bellhouse, B. J. (1972). The fluid mechanics of the aortic valve. In Biological Tissue in Heart Valve Replacement, edited by M. I. Ionescu, D. N. Ross, and G. H. Wooler, p. 23. Butterworths, London.

Duran, C. G., Manley, G., and Gunning, A. J. (1965). The behaviour of homotransplanted aortic valves in the dog. Brit. J. Surg. 52, 549.

Holden, M. P. and Ionescu, M. I. (1973a). Functional characteristics of three cusp tissue valves: a pulse duplicator study. Ann. thorac. Surg. (in press).

$\longrightarrow$, and - (1973b). Failure of autologous fascia lata valves in the mitral position: An explanation. $J$. thorac. cardiovasc. Surg. (in press).

- Wooler, G. H., Catchpole, L., and Ionescu, M. I. (1973). A pulse duplicator for the study of opening characteristics of tissue heart valves. Cardiovasc. Res. (in press).

Hudson, R. E. B. (1970). Discussion. First International Round Table on Fascia Lata Heart Valves. Toronto, 10-11 October.

Ionescu, M. I., Deac, R. C., Whitaker, W., Wooler, G. H. (1972a). Fascia lata heart valves. In Biological Tissue in Heart Valve Replacement, edited by M. I. Ionescu, D. N. Ross, and G. H. Wooler, p. 617. Butterworths, London.

—, Pakrashi, B. C., Holden, M. P., Mary, D. A., and Wooler, G. H. (1972b). Results of aortic valve replacement with frame-supported fascia lata and pericardia grafts. J. thorac. cardiovasc. Surg., 64, 340.

—, and Ross, D. N. (1969). Heart valve replacement with autologous fascia lata. Lancet, 2, 335.

, - _ Wooler, G. H., Deac, R. C., and Ray, D. (1970). Replacement of heart valves with autologous fascia lata. Surgical technique. Brit. J. Surg., 57, 437. 
Lam, C. R., Aram, H. H., and Munnell, E. R. (1952). An experimental study of aortic valve homografts. Surg. Gynec. Obstet., 94, 129.

Silver, M. D., and Trimble, A. S. (1972). Structure of autologous fascia lata heart valve prosthesis. Arch. Path., 93, 109.
Spiers, H. M. (1962). Technical Data on Fuel, 6th ed., rev 2nd impression. British National Committee, World Power Conference, London.

Trimble, A. S. (1972). First International Round Table on $\frac{\mathscr{\sigma}}{\overparen{D}}$ Fascia Lata Heart Valves. Surgery, 71, 10.

Requests for reprints to $M$. I. Ionescu, Department of Cardiothoracic Surgery, The General Infirmary at Leeds. 